\title{
Corpo ciborgue e as marcas de gênero no Orkut: Lugar de mulher é no tanque?
}

Resumo: A intensa conexão com as tecnologias é cada vez mais presente na vida cotidiana, especialmente nos meios de comunicação, em que as comunidades virtuais, como o site de relacionamentos Orkut, são uma verdadeira febre nacional. No universo ciberespacial, o Orkut assume uma posição prestigiada, afinal é hoje um dos endereços eletrônicos mais acessados no Brasil. Neste artigo o Orkut é analisado como um currículo cultural que ensina diferentes modos de ser e de estar no mundo, que participa do processo de constituição das subjetividades juvenis na contemporaneidade. A análise tem por foco algumas marcas de gênero nas subjetividades divulgadas no discurso sobre o corpo de uma comunidade do Orkut. A metodologia utilizada foi a netnografia aplicada ao ciberespaço orkuteiro. As análises empreendidas têm como referencial teórico os estudos de gênero e ciborgue. O argumento desenvolvido é de que na comunidade Lugar de mulher é no tanque divulgam-se determinadas maneiras de as/os jovens conduzirem suas condutas pautadas em uma coisificação do corpo masculino ciborguizado. Mostramos na análise, como os modos demandados para a condução da existência juvenil transgridem e ao mesmo tempo reafirmam as fronteiras culturais de gênero. Há uma multiplicidade de sentidos divulgados que compõem uma hibridização das subjetividades engendradas no discurso analisado.

Palavras-chave: Corpo. Ciborgue. Orkut. Gênero. Juventude.

Celulares, MP3, MP4, lap tops, palm tops, netbooks e inúmeros gadgets buscam garantir a comunicação permanente e a conexão intensa entre as pessoas. Comunicação e conexão mediadas, cada vez mais, pelas tecnologias digitais. Neste contexto não há dúvida de que, na contemporaneidade, circulam diferentes formas de vida que estão configurando um novo tempo. Um tempo que algumas/alguns autoras/es denominam "pós-moderno". (SILVA, 1996; PETERS, 2000) Tempo que tem constituído um cenário de composição de novas formas de viver. Tendo como referência esse cenário e o que nele se produz, este artigo busca compreender o tipo de subjetividade juvenil demandada e produzida no currículo de algumas comunidades do Orkut.

O Orkut é o site de relacionamentos mais difundido no Brasil e um dos mais populares do mundo. Segundo o Instituto Brasileiro de Opinião Pública e Estatística (IBOPE), durante o mês de janeiro de 2008, enquanto o e-mail foi acessado durante uma hora e nove minutos, o Orkut ocupou mais de cinco horas do tempo
Shirlei Rezende Sales Professora Adjunta do Departamento de Administração da Faculdade de Educação da UFMG shirlei.sales@hotmail.com

Marlucy Alves Paraíso Professora do Programa de PosGraduação em Educação da FaE/ UFMG

marlucy.paraiso@terra.com.br 
(1) Disponível em: <http://www. ibope.com.br/calandraWeb/servlet/ CalandraRedirect?temp $=5 \&$ proj $=$ PortallBOPE \&pub $=T \& d b=c a l d b \& c$ omp $=$ IBOPE + M\%EDdia\&docid $=E$ D76CFF5899DD2048325740C004 B8DA3 > Acesso em: 7 mar. 2009.

(2) Disponível em: <http://www. alexa.com> Acesso em: 20 jun. 2011.

das/os internautas brasileiras/os ${ }^{1}$, as/os quais, em 2009, já somam mais de 50 milhões. O Orkut é um dos endereços eletrônicos mais acessados no País ${ }^{2}$.

Neste artigo, o Orkut é analisado como um currículo cultural, o qual é definido como parte de uma "pedagogia cultural" que, "[...] de maneira mais ampla, nos ensina comportamentos, procedimentos, hábitos, valores e atitudes, considerados adequados e desejáveis, através de diferentes artefatos, como o cinema, a televisão, as revistas, a literatura, a moda, a publicidade, a música etc". (PARAÍSO, 2001, p. 144) É preciso explicitar aqui que essa definição remete à importância de se pesquisar outros currículos além do escolar, sem desconsiderar, no entanto, que o próprio currículo escolar também é um artefato cultural da maior importância na produção e na divulgação de significados e de sujeitos de determinados tipos. (PARAÍSO, 2001)

A metodologia utilizada é a netnografia. Enquanto um método de pesquisa derivado da etnografia (ROCHA, 2006), a netnografia utiliza os conceitos da etnografia, de modo resignificado (PINTO et. al., 2007), aplicados ao universo ciberespacial, para a análise da cibercultura. Uma adaptação consiste exatamente na observação participante no ciberespaço, cuja natureza é desterritorializada. No caso das comunidades virtuais como, por exemplo, o Orkut, a netnografia deve combinar as observações com participação efetiva e imersiva nas comunidades pesquisadas. (CARVALHO, 2006)

O foco de análise incide sobre a comunidade do Orkut: Lugar de mulher é no tanque e desenvolve o argumento de que na comunidade divulgam-se determinadas maneiras de as/os jovens conduzirem suas condutas pautadas em uma coisificação do corpo masculino ciborguizado. Mostramos na análise como os modos demandados para a condução da existência juvenil transgridem e ao mesmo tempo reafirmam as fronteiras culturais de gênero. Há uma multiplicidade de sentidos divulgados que compõem uma hibridização das subjetividades engendradas no discurso analisado.

\section{O orkut e a produção de subjetividades juvenis}

Ao entender que o Orkut tem uma pedagogia, que ensina diferentes formas de ser e de estar no mundo, que participa do processo de constituição de modos de existência específicos, considero-o como um currículo cultural. O currículo cultural revela um apagamento das fronteiras entre as diferentes instituições sociais como 
a educação e a mídia, por exemplo, e mostra-se envolvido com o processo de produção de subjetividades juvenis.

As subjetividades juvenis são alvo de muitos investimentos discursivos na contemporaneidade. Isso pode ser visto em variadas peças publicitárias que divulgam o jeito jovem de agir, de viver, de se vestir, de se divertir, de falar, de se comportar, de se conduzir. Ela está presente em outros artefatos culturais, como telenovelas, músicas, cinema, programas televisivos, revistas, etc. Os discursos que circulam nesses meios e em outros, como a escola e o ciberespaço, se articulam na fabricação de determinados modos de ser jovem.

Inspirado nos estudos de Michel Foucault, este artigo analisa o processo de produção das subjetividades juvenis com base no entendimento de subjetividade como uma construção discursiva, produzida por meio de diferentes técnicas, procedimentos, exercícios e práticas. Nos mais diversificados discursos, por meio de várias técnicas, tecnologias e estratégias, são produzidas subjetividades de determinados tipos. Discursos são aqui compreendidos, na acepção foucaultiana, como "[...] práticas que formam sistematicamente os objetos de que falam". (FOUCAULT, 2005, p. 55) A produção das subjetividades, por sua vez, se dá por meio da articulação entre as técnicas de dominação e as técnicas de si. As "técnicas de dominação" localizam-se no âmbito da relação com o poder; estão mais voltadas para a condução da conduta da/o outra/o; agem na dominação dos indivíduos uns sobre os outros. (FOUCAULT, 1993) Já as "técnicas de si" referem-se à relação consigo e são definidas como aquelas que

[...] permitem aos indivíduos efetuarem um certo número de operações sobre seus corpos, sobre suas almas, sobre seu próprio pensamento, sobre sua própria conduta, e isso de tal maneira a transformarem-se a eles próprios, a modificarem-se, ou a agirem num certo estado de perfeição, de felicidade, de pureza, de poder sobrenatural e assim por diante. (FOUCAULT, 1993, p. 207)

As técnicas de si são usadas pelo indivíduo para falar sobre si e produzir verdades sobre si, expondo-as a outrem. Como mostra Foucault (1993, p. 212), "[...] esta verdade é obtida pela retórica e pela explanação". Por meio da "verbalização da verdade sobre si", de forma exaustiva e permanente, torna-se visível o próprio eu. Essa verbalização consiste em "confessar", em revelar o eu, o que se constitui uma prova de verdade. (FOUCAULT, 1993, p. 218) 
Para produzir essa verdade sobre si, o indivíduo vivencia uma série de exercícios, ou seja, de "práticas de si", as quais "não são 'inventadas' pelos indivíduos, mas constituem esquemas que eles encontram em sua cultura e que lhes são propostos, sugeridos, impostos pela sociedade e grupos sociais". (CORAZZA, 2004, p. 61) A partir desses exercícios, entre os quais se destacam o "autoexame" e a "Confissão" (FOUCAULT, 1993, p. 212), configura-se aquilo que o autor definiu como uma "autorevelação", que é simultaneamente uma "autodestruição", pois deve-se romper com as verdades produzidas sobre si, com o próprio eu construído, e produzir outras verdades demandadas por determinadas estratégias de governo.

A noção de que a subjetividade é fabricada discursivamente, por meio de inúmeros procedimentos e técnicas, é importante para a compreensão da juventude contemporânea, para o entendimento de suas formas de viver, seus modos de se colocar nas mais diversificadas situações, bem como os múltiplos sentidos produzidos para suas experiências. Articulando essa noção de subjetividade a toda uma teorização sobre cultura feita pelos Estudos Culturais, pode-se dizer que a subjetividade é produzida na e por meio da cultura. Afinal, a cultura disponibiliza uma série de procedimentos que os indivíduos devem aplicar sobre si e sobre os outros a fim de regular os comportamentos. (HALL, 1997) Na cultura também são estabelecidos os padrões que vão servir de parâmetro para o julgamento das condutas e criar a demanda pela modificação daquilo que não está de acordo com a referência. (HALL, 1997) No caso da subjetividade juvenil, a cibercultura consiste uma proeminente dimensão da constituição da juventude. Daí a relevância de se investigar a interface entre a subjetividade juvenil, a cultura juvenil e as tecnologias digitais.

\section{Ciborguização juvenil}

O impulso tecnológico, com o avanço da informática e de outras tecnologias como a nano e biotecnologia, a engenharia genética, a robótica, a engenharia biônica e de materiais, a eletrônica molecular, etc tem intensificado a integração entre as pessoas e as máquinas. Integração que consiste em um "[...] tipo especial de relação entre o sistema humano e o sistema mecânico, no qual se evidencia - parcial ou totalmente - uma dissolução dos limites entre ambos sistemas". (KOVAL, 2006, p. 2, tradução nossa) A integração pode se 
dar ao menos de duas formas. Uma delas, a "integração exógena", resulta em uma espécie de humanização das máquinas, segundo uma lógica mimética, em uma simulação artificial do ser humano no processo de construção de máquinas, robôs, etc. A segunda forma, "integração endógena", visa potencializar as habilidades humanas por meio de próteses e outros artigos tecnológicos, em uma espécie de maquinização do humano. (KOVAL, 2006) É esse segundo tipo de integração que interessa a esta pesquisa, pois é por meio dela que se constituem os seres denominados ciborgues.

Ciborgue é o termo que resulta da contração de cybernetis organism, cunhado em 1960 por Mafred Clynes e Nathan Kline (SANTAELLA, 2003; KIM, 2004; KOVAL, 2006; LIMA, 2007), "em um simpósio sobre os aspectos psico-fisiológicos do vôo espacial". (KIM, 2004, p. 208) Em 1972, sob inspiração da ideia de Clynes e Kline, Martin Caidin escreve o livro de ficção científica Cyborg (KIM, 2004; BRUNI, 2008), no qual a figura do ciborgue aparece como uma forma de reconstruir e superar a natureza humana. A/o ciborgue consiste em "[...] um organismo cibernético, um híbrido de máquina e organismo". (HARAWAY, 2000, p. 40) É um ser "[...] entremeio artificial-natural, não é nem isso nem aquilo, não conhece a oposição binária que de certo modo estrutura o pensamento ocidental. É a junção entre o isso e o aquilo". (COUTO, 2001, p. 5) A/o ciborgue é, pois, um "[...] organismo capaz de integrar componentes externos para expandir as funções que regulam seu corpo e dessa forma adaptar-se a novos entornos". (KOVAL, 2006, p. 11) Ela/e anuncia a imagem de um ser humano "[...] 'melhorado' com a acoplagem da tecnologia e cada vez mais além das limitações de desempenho ditadas pela natureza". (KIM, 2004, p. 210)

Com a multiplicação dos artefatos tecnológicos, nos últimos tempos, a noção de ciborgue tem-se ampliado para toda pessoa que tem sua vida mediada pela tecnologia, como se fôssemos "[...] desde o nascimento, essas criaturas em devir adaptativo com a tecnocultura que nos rodeia". (BRUNI, 2008, p. 6) Nesse sentido, hoje, seríamos todas/os ciborgues (HARAWAY, 2000; KOVAL, 2006), afinal utilizamos telefones, calculadoras, computadores, automóveis, diversos tipos de próteses e mais uma enorme variedade de dispositivos tecnológicos que tende ao infinito. Em nós se desfazem as fronteiras entre o humano e o animal; entre animal-humano e máquina; entre físico e não-físico. Isso porque o que caracteriza a/o ciborgue é justamente o hibridismo, a mistura, a montagem 
(3) Disponível em < http://www. orkut.com > Acesso em: 19 jan. 2008.

(4) Disponível em < http://www. orkut.com > Acesso em: 19 jan. 2008.

(5) Disponível em < http://www. orkut.com > Acesso em: 19 jan. 2008.

(6) Disponível em < http://www. orkut.com > Acesso em: 19 jan. 2008. que desmancha qualquer tipo de dualismo em nossa composição. A "confusão" de limites entre organismo/máquina, natural/artificial, natureza/cultura se combina na configuração da/o ciborgue.

Essa dissolução de fronteiras, de acordo com Haraway (2000), é ambivalente, pois produz uma série de potencialidades de vida e de análise, mas gera alguns riscos, especialmente no atual contexto histórico que configura a dinâmica da dominação e da opressão. A autora, inspirada em Bruno Latour, adverte que assim como "a ciência e a tecnologia fornecem fontes renovadas de poder, [... nós precisamos de fontes renovadas de análise e de ação política". (HARAWAY, 2000, p. 74) Desse modo, ela defende que, com a/o ciborgue, a teoria não pode mais ser universal ou totalizante. Ao contrário, deve incidir sobre a construção e a desconstrução de fronteiras e escapar do "labirinto dos dualismos" (HARAWAY, 2000, p. 108), rumo a uma multiplicidade de diferentes explicações.

De acordo com esses pressupostos, pode-se afirmar que, na atualidade, estamos vivendo em uma "ecologia digital" (GREEN; BIGUM, 2003, p. 229) repleta de novas subjetividades forjadas nas relações sociais estabelecidas por meio das tecnologias digitais. É como se máquinas e seres humanos fossem fundidos em uma espécie de amálgama, constituindo novas formas de vida: as/os ciborgues. (GREEN; BIGUM, 2003) Elas/es seriam novas espécies, com habilidades, desejos, formas de pensamento, estruturas cognitivas, temporalidade, localização espacial diferentes e ampliadas pelas tecnologias digitais.

\section{O jovem sarado: Corpo ciborguizado}

A comunidade do Orkut Lugar de mulher é no tanque possui 610.966 membros $^{3}$ e exibe no avatar o tórax e o abdômen de um homem esculpidos pela musculação. A descrição traz "PARA AS MULHERES QUE GOSTAM DESTE CANTINHO ACONCHEGANTE

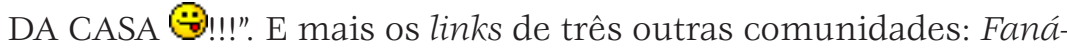
ticos por academia e musculação (com 62.884 membros $^{4}$ ); Lugar de homem é na cama, (com 10.074 participantes $^{5}$ ) e Lugar de homem é na cozinha (com 33.873 usuárias/os ${ }^{6}$ ). Todas essas comunidades têm em seu avatar corpos masculinos bem-definidos pela malhação e pertencem a um mesmo dono, um rapaz que se define em seu perfil particular como "fanático por musculação". Nas comunidades são divulgados corpos ciborgues, modificados pela intensa ativida- 
de física, provavelmente melhorados por meio da intervenção de vitaminas, suplementos alimentares ou, até mesmo, anabolizantes. O corpo ciborgue é composto por uma combinação de elementos naturais e artificiais "[...] que cria criaturas tecnicamente melhoradas. É um corpo fortalecido, construído como uma máquina de alta performance". (COUTO, 2009, p. 5) É também um corpo erotizado, cujo "lugar" é a cama, transmutado "[...] em um progressivo upgrade corporal promovido e festejado em nome da eficiência, da beleza, da juventude, da boa forma, do gozo eterno, da saúde total". (COUTO, 2009, p. 10)

A prática de atividades físicas tem sido alvo de discussões no campo da Educação ${ }^{7}$. Os trabalhos mostram que as disputas são intensas entre o que pode ser definido como um "estilo de vida saudável" e aquilo que possa ser descrito como falta, no caso do "estilo sedentário" de viver, ou como excesso, no caso das/os "fanáticas/ os pela boa forma". Trata-se então de encontrar a medida certa de investimento em atividade física para se atingir rendimentos que garantam o estado saudável e normal.

A proposta da comunidade, no entanto, não parece evocar a preocupação com o equilíbrio certo de malhação. Ela parece trazer o músculo como "protagonista do espetáculo contemporâneo, exigindo detalhadas formas de gerenciamento do próprio corpo para obtenção/ampliação da robustez, velocidade e resistência". (FRAGA, 2000, p. 138) A musculatura arduamente esculpida é apresentada como símbolo de beleza e virilidade, o que faz dos homens sarados alvo da admiração e do desejo tanto de ter um corpo equivalente, quanto de possuí-lo afetiva e/ou sexualmente. Esses corpos delineados partem de uma "representação de beleza que tem como sua expressão máxima a harmonia e a proporção das formas corporais, tentando reproduzir o que uma vez se considerou corpo verdadeiro de deuses e deusas, de heróis olímpicos ou de pessoas perfeitas". (GOELLNER, 2000, p. 84)

A própria denominação "sarado" carrega, ao menos, uma tripla conotação. O sentido evocado mais imediatamente remete à ideia de um corpo delineado pela malhação. Simultaneamente remete-se a um corpo saudável, são. Há ainda o sentido de curado, como se a atividade física pudesse transformar o corpo doente, curando-o. Tais sentidos se somam na construção de uma imagem de corpo ideal, o qual é divulgado como meta a ser atingida.
(7) Alguns exemplos podem ser vistos em Fraga $(2000,2005)$, Goellner (2000, 2003), Goellner e Fraga (2004) e Andrade (2004). 
A presença masculina na comunidade demonstra que o jogo de subjetivação não atinge apenas as garotas. Eles também entram no jogo e passam a disputar quem consegue "orgulhosamente ostentar a melhor 'pose'". (FRAGA, 2000, p. 138) Talvez essa comunidade seja enunciada como bizarra pelo jogo de sentidos que ela proporciona. O título da comunidade utiliza uma expressão de cunho machista lugar de mulher é no tanque, como se a mulher devesse ficar restrita ao lar, realizando tarefas domésticas como lavar a roupa da casa. O título utiliza uma enunciação que remete a elementos de uma cultura machista, mas, ao ser traduzida na cibercultura, aciona outros sentidos. Outros elementos da cultura orkuteira como avatar e a descrição da comunidade demonstram que a proposta não se refere aos serviços domésticos, nem ao posicionamento da mulher na função de dona de casa. Ao contrário, a imagem do avatar exibe o corpo masculino escultural, com um abdome na forma de tanquinho apresentado como objeto de desejo afetivo/sexual e como meta a ser atingida pelos homens em busca do corpo perfeito.

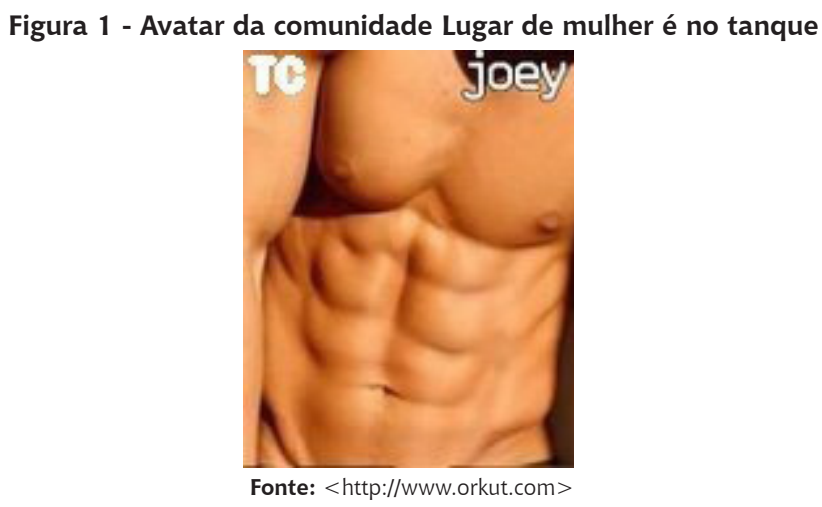

O resultado da composição da comunidade é híbrido. Título, descrição e avatar confundem os sentidos e não permitem uma classificação rígida e estática de sua proposta. Essa mistura, que foge a qualquer categorização estanque, é exemplar do jeito ciborgue de ser.

O discurso sobre a busca do corpo esculpido incide não só sobre os garotos, mas também sobre as garotas. O currículo do Orkut não ensina apenas aos garotos como devem produzir seus corpos, mas às garotas o tipo de corpo que elas devem admirar e desejar. As relações de poder e de gênero estão presentes também no Orkut 
mostrando que há atualmente "[...] uma multiplicidade de sujeitos e de práticas [o que] sugere o abandono do discurso que posiciona, hierarquicamente, o centro e margens em favor de outro discurso que assume a dispersão e circulação do poder". (LOURO, 2005, p. 51) Tal multiplicidade tem como efeito uma hibridação de sentidos e de composição das subjetividades juvenis.

Em síntese, este artigo discute a produção de certos tipos de subjetividades juvenis articuladas em torno do corpo ciborgue e das relações de gênero, compreendendo que a produção das subjetividades não se dá de maneira coerente e linear. Esse processo engendra o hibridismo, em que a juventude contemporânea negocia sentidos, confunde posições, perturba as certezas, desliza de um ponto a outro, escapa a categorizações estanques, não se deixa aprisionar por rótulos e etiquetas predeterminadas. Juventude ciborgue $e$ alienígena $e$ humana $e$ híbrida $e$ transgressora $e$ conservadora $e$ machista $e$ feminista $e$ muito mais...

\section{Cyborg body and the marks of gender in orkut: woman's place is in the tank ${ }^{8}$ ?}

\begin{abstract}
The intense connection to technology is increasingly present in everyday life, especially in the media, in which virtual communities like social networking site Orkut, is a boom country. In the cyber universe, Orkut takes a prestigious position, after all is today one of the most accessed site in Brazil. In this article, Orkut is analyzed as a cultural curriculum that teaches different ways of being, and being in the world that participates in the formation of subjectivities in contemporary youth. The analysis is focused on some brands of gender subjectivities disclosed in the discourse on the body of an Orkut community. The used methodology was the netnography applied to the Orkut cyberspace. Analyses are undertaken as theoretical studies of gender and cyborg. The argument developed in the community is that woman's place is in the tank to disclose certain ways of the young people conduct their conduct linked to an objectification of the male body on the cyberspace. We show in the analysis as modes demanded for the conduct of youth transgress existence while reaffirming the cultural boundaries of gender. There are a multiplicity of meanings disclosed that comprise a hybridization of engendered subjectivities in discourse analysis.
\end{abstract}

Keywords: Body. Cyborg. Orkut. Gender. Youth.

\section{Referências}

ANDRADE, Sandra dos Santos. Representações de corpo feminino na revista Boa Forma. In: CARVALHO, Marie Jane Soares; ROCHA, Cristianne Maria Famer (Org.). Produzindo gênero. Porto Alegre: Sulina, 2004. p. $143-52$.

BRUNI, Paolo. Como os videogames formam ciborgues? Trabalho apre-
(8) "Tank" in Portuguese is also a space for washing cloths and muscular chest and abs. 
sentado no IV Seminário Jogos Eletrônicos, Educação e Comunicação, Salvador, 2008. Disponível em: < http://www.comunidadesvirtuais.pro. $\mathrm{br} / \mathrm{seminario} 4 / \mathrm{trab} / \mathrm{pb} . \mathrm{pdf}>$.

Acesso em: 2 out. 2010.

CARVALHO, Ana Beatriz G. Etnografia digital na educação a distância e usos de jogos eletrônicos no processo de ensino e aprendizagem. Trabalho apresentado no 3 Seminário Jogos Eletrônicos, Educação e Comunicação - Construindo Novas Trilhas, Campina Grande, 2006. Disponível em: < http://www.gente.eti.br/site/index.php?option = com_contentEv iew $=$ article $\mathcal{E} \mathrm{id}=37$ :etnografia-digital-na-educacao-a-distancia-e-uso-de-jogos-eletronicos-no-processo-de-ensino-e-aprendizagem\& catid = 6:artigos-de-ana-beatriz-carvalho\&Itemid =27 > . Acesso em: 30 out. 2010.

CORAZZA, Sandra Mara. O que quer um currículo? pesquisas pós-críticas em educação. 3. ed. Petrópolis, RJ: Vozes, 2004.

COUTO, Edvaldo Souza. Políticas do pós-humano: interfaces dos corpos, das sexualidades e das tecnologias digitais. In: REUNIÃO ANUAL DA ANPED, 32., 2009. Caxambu, MG. Sociedade, cultura e educação: novas regulações? Caxambu, MG: ANPEd, 2009.

O zumbido do híbrido: a filosofia ciborgue do corpo. Revista Margem, São Paulo, n. 13, p. 85-99, jun. 2001.

FOUCAULT, Michel. A arqueologia do saber. 7. ed. Rio de Janeiro: Forense Universitária, 2005.

. Verdade e subjetividade. Revista de Comunicação e Linguagem, Lisboa, n.19, p. 203-23, 1993.

FRAGA, Alex Branco. Anatomias de consumo: investimentos na musculatura masculina. Educação \& Realidade, Porto Alegre, v. 25, n. 2, p. 135-150, jul./dez. 2000.

GOELLNER, Silvana Vilodre. A boa forma de João e o estilo de vida de Fernanda. In: LOURO, Guacira Lopes; FELIPE, Jane; GOELLNER, Silvana (Org.). Corpo, gênero e sexualidade: um debate contemporâneo sobre educação. 2. ed. Petrópolis, RJ: Vozes, 2005. p. 95-107.

. O esporte e a espetacularização dos corpos femininos. Labrys Estudos Feministas. n. 4, ago./dez. 2003. Disponível em: < http://www. unb.br/ih/his/gefem/labrys4/textos/silvanal.htm > Acesso em: 5 ago. 2008.

Mulheres em movimento: imagens femininas na Revista Educação Physica. Educação \& Realidade, Porto Alegre, v. 25, n. 2, p. 77-94, jul./dez. 2000.

; FRAGA, Alex Branco. O espetáculo do corpo: mulheres e exercitação física no início do século XX. In: CARVALHO, Marie Jane Soares; ROCHA, Cristianne Maria Famer (Org.). Produzindo gênero. Porto Alegre: Sulina, 2004. p. 161-71.

GREEN, Bill; BIGUM, Chris. Alienígenas na sala de aula. In: SILVA, To- 
maz Tadeu da (Org.). Alienígenas na sala de aula: uma introdução aos estudos culturais em educação. 5. ed. Petrópolis, RJ: Vozes, 2003. p. 208-43.

HALL, Stuart. A centralidade da cultura: notas sobre as revoluções culturais do nosso tempo. Educação \& Realidade, Porto Alegre, v. 22, n. 2, p. 15-46, jul./dez. 1997.

HARAWAY, Donna J. Manifesto ciborgue: ciência, tecnologia e feminismo-socialista no final do século XX. In: SILVA, Tomaz Tadeu da (Org.). Antropologia do ciborgue: as vertigens do pós-humano. Belo Horizonte: Autêntica, 2000. p. 37-129.

KIM, Joon Ho. Cibernética, ciborgues e ciberespaço: notas sobre as origens da cibernética e sua reinvenção cultural. Horizontes Antropológicos, Porto Alegre, ano 10, n. 21, p. 199-219, jan./jun. 2004.

KOVAL, Santiago. Andróides y posthumanos: la integración hombre-máquina. 2006. Disponível em: < http://www.diegolevis.com.ar/secciones/articulos.html\#Autores > Acesso em: 1 jul. 2009.

LIMA, Homero Luís Alves. Corpo cyborg e o dispositivo das novas tecnologias. In: COUTO, Edvaldo Souza; GOELLNER, Silvana Vilodre (Org.). Corpos mutantes: ensaios sobre novas (d)eficiências corporais. Porto Alegre: Editora da UFRGS, 2007.

LOURO, Guacira Lopes. Currículo, gênero e sexualidade. O "normal", o "diferente" e o "excêntrico". In: FELIPE, Jane; GOELLNER, Silvana (Org.). Corpo, gênero e sexualidade: um debate contemporâneo sobre educação. 2. ed. Petrópolis, RJ: Vozes, 2005. p. 9-27.

PARAÍSO, Marlucy Alves. A produção do currículo na televisão: que discurso é esse? Educação e Realidade, Porto Alegre, v. 26, n. 1, p. 14160, jan./jun. 2001.

PETERS, Michael. Pós-estruturalismo e filosofia da diferença: uma introdução. Belo Horizonte: Autêntica, 2000.

PINTO, Virginia Bentes et al. "Netnografia": uma abordagem para estudos de usuários no ciberespaço In: CONGRESSO NACIONAL DE BIBLIOTECÁRIOS, ARQUIVISTAS E DOCUMENTALISTAS, 9, 2007, Lisboa. Lisboa: APBAD, 2007. p. 79-95. Disponível em < http:// badinfo. apbad.pt/Congresso9/COM90.pdf> Acesso em: $28 \mathrm{dez} .2009$.

ROCHA, Paula Jung. Jornalismo em tempos de cibercultura: um estudo do ClicRBS. 2006. Tese (Doutorado em Comunicação Social) - Faculdade de Comunicação Social/PUCRS, Porto Alegre, 2006.

SANTAELLA, Lucia. Culturas e artes do pós-humano: da cultura das mídias à cibercultura. São Paulo: Paulus, 2003.

SILVA, Tomaz Tadeu da. Identidades terminais: as transformações na política da pedagogia e na pedagogia da política. Petrópolis, RJ: Vozes, 1996.

Artigo submetido em 01/07/2011 e aceito para publicação em 03/10/2011 